\title{
Pneumothorax in a Patient Posted for Cervical Spine Surgery
}

\author{
${ }^{1}$ Naina P Dalvi, ${ }^{2}$ Nilam D Virkar
}

\section{ABSTRACT}

A 54-year-old female posted for cervical laminectomy was started on antihypertensive drugs on admission. Magnetic resonance imaging showed cervical degeneration with posterior disk herniation at $\mathrm{C}_{3}-\mathrm{C}_{4}$ and disk bulge at $\mathrm{L}_{5}-\mathrm{S}_{1}$. After attaching the monitors, patient was premedicated and anesthetized. During mask ventilation, abdomen gradually distended. After intubation under vision, reduced air entry on right side and increased resistance was felt during manual ventilation. Salbutamol puff was given through endotracheal tube. Still air entry remained decreased on right side. X-ray and $\mathrm{C}$-arm showed right-sided pneumothorax. Inter-costal drainage (ICD) was inserted in right 5th intercostal space in midaxillary line. Post-ICD X-ray showed significant expansion of right lung. Patient was ventilated and extubated after 4 hours. Highresolution computerized tomography confirmed the diagnosis. Surgery was rescheduled. On the 8th day, patient developed purulent drainage through ICD in the ward. She was diagnosed to have pulmonary Koch's and was treated successfully.

Keywords: Laminectomy, Tension pneumothorax, Tuberculosis.

How to cite this article: Dalvi NP, Virkar ND. Pneumothorax in a Patient Posted for Cervical Spine Surgery. Res Inno Anaesth 2016;1(1):32-34.

Source of support: Nil

Conflict of interest: None

\section{INTRODUCTION}

Pneumothorax occurs when intrapleural pressures exceed the atmospheric pressure. It causes collapse of the lung and increase in the airway pressure. As the intrathoracic pressures increase more than cardiac filling pressures, it limits the stroke volume and cardiac output leading to life-threatening hypotension and hemodynamic instability. Intraoperative pneumothorax is a life-threatening emergency, which needs rapid intervention.

\footnotetext{
${ }^{1}$ Additional Professor, ${ }^{2}$ Assistant Professor

${ }^{1}$ Department of Anaesthesia, HBTMC and Dr RN Cooper Hospital, Mumbai, Maharashtra, India

${ }^{2}$ Department of Anaesthesia, LTMMC and LTMG Hospital Mumbai, Maharashtra, India

Corresponding Author: Naina P Dalvi, Additional Professor, Department of Anaesthesia, HBTMC and Dr RN Cooper Hospital, Vile Parle, Mumbai, Maharashtra, India Phone: +919820711656, e-mail: drnaina@rediffmail.com
}

\section{CASE REPORT}

A 54-year-old female was admitted with pain in the neck radiating to both arms, tingling numbness in the fingers, and pain in the lower back radiating to lower limbs with difficulty in walking since 2 years.

On preoperative evaluation, blood investigations were normal; chest X-ray showed increased bronchovascular markings. She was diagnosed to have hypertension and was started on T. Amlodipine $5 \mathrm{mg}$ twice daily and T. Losartan $12.5 \mathrm{mg}$ once daily. Her two-dimensional echo showed mild pulmonary hypertension $40 \mathrm{~mm} \mathrm{Hg}$ with ejection fraction 60\%. Magnetic resonance imaging showed cervical degenerative spondyloarthropathy with posterior cervical disk herniation at $\mathrm{C}_{3}-\mathrm{C}_{4}$ and canal stenosis of L2-L5 with disk bulge at $\mathrm{L}_{5}-\mathrm{S}_{1}$.

Patient was first operated for $\mathrm{L}_{5}-\mathrm{S}_{1}$ laminectomy. Postoperatively, she was electively ventilated due to prolonged duration of surgery and inadequate respiratory efforts and was extubated 12 hours later.

Patient was posted for cervical laminectomy after 30 days of the lumbar surgery. Preoperative pulse was $130 / \mathrm{min}$, blood pressure (BP) $130 / 90 \mathrm{~mm} \mathrm{Hg}$, and arterial oxygen saturation $99 \%$. Patient was taken to the operation table. Cardioscope, pulsoxymeter, and noninvasive BP monitor were attached. Patient was premedicated with Inj. Glycopyrrolate $0.2 \mathrm{mg}$, Inj. Midazolam $1 \mathrm{mg}$, and Inj. Pentazocine $18 \mathrm{mg}$. After giving Inj. Thiopental sodium $5 \mathrm{mg} / \mathrm{kg}$, ventilation was checked and rocuronium 1 $\mathrm{mg} / \mathrm{kg}$ was given. During mask ventilation with oxygen, nitrous oxide, and sevoflurane, resistance was felt and chest expansion was found to be inadequate. Head was repositioned and triple airway maneuver was performed. The resistance still persisted. Abdomen gradually distended, hence nitrous oxide was switched off. Under laryngoscopic vision, 7 no. cuffed polyvinyl chloride endotracheal tube was inserted. Air entry was found to be decreased on the right side. Increased resistance was felt during manual ventilation and airway pressure went up to $35 \mathrm{~cm} \mathrm{H}_{2} \mathrm{O}$. Endotracheal tube and circuit were checked thoroughly for any kink and displacement. Nasogastric tube was inserted to decompress the stomach. Abdominal distension though reduced persisted with resistance to ventilation. Salbutamol metered dose puff was given through endotracheal tube to rule out bronchospasm. Air entry remained persistently decreased on the right side. 


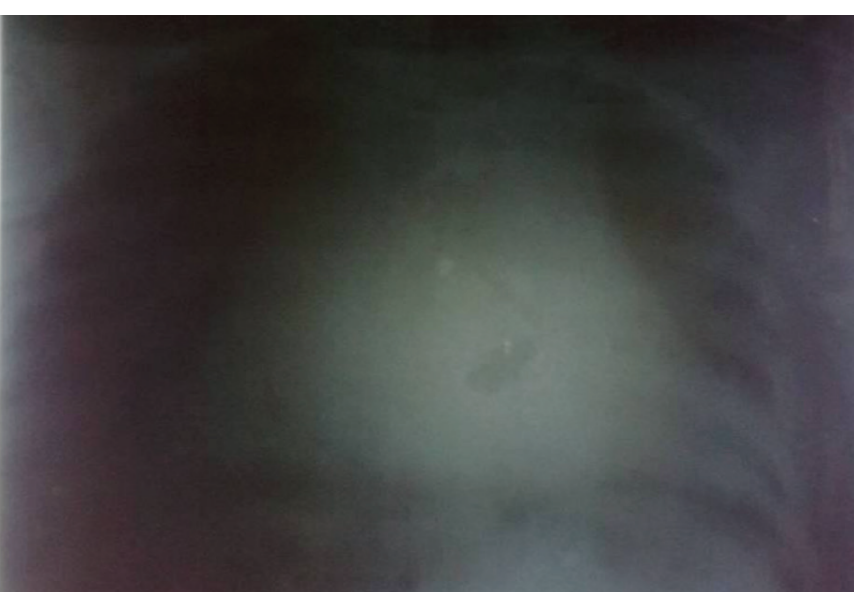

Fig. 1: Intraoperative pneumothorax

Arterial oxygen saturation was maintained throughout. Making use of C-arm and X-ray available in the operation theater, right pneumothorax was identified immediately (Fig. 1). Implantable cardioverter defibrillator was inserted in right 5 th intercostal space in midaxillary line. Gush of air was heard. Implantable cardioverter defibrillator was kept in underwater seal. Post-ICD X-ray chest showed significant expansion of the right lung. Surgery was postponed and patient was extubated after 4 hours (Fig. 2).

High-resolution computerized tomography showed pneumothorax on right side with collapse. Few fibrobronchiectatic and fibrocalcific changes in left lung were seen. Subcutaneous emphysema was seen in right chest wall and right breast (Fig. 3).

On the 8th day, patient developed tachypnea and desaturation with purulent drainage through ICD and was started on higher antibiotics. The pleural effusion

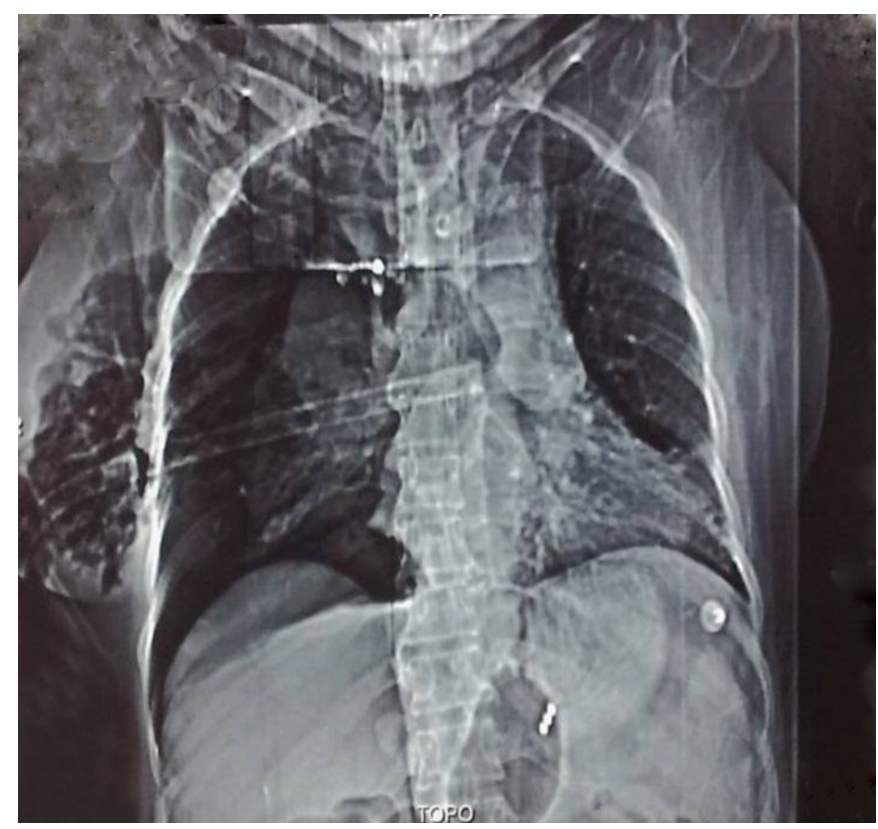

Fig. 3: Right pneumothorax on CT scan day 2

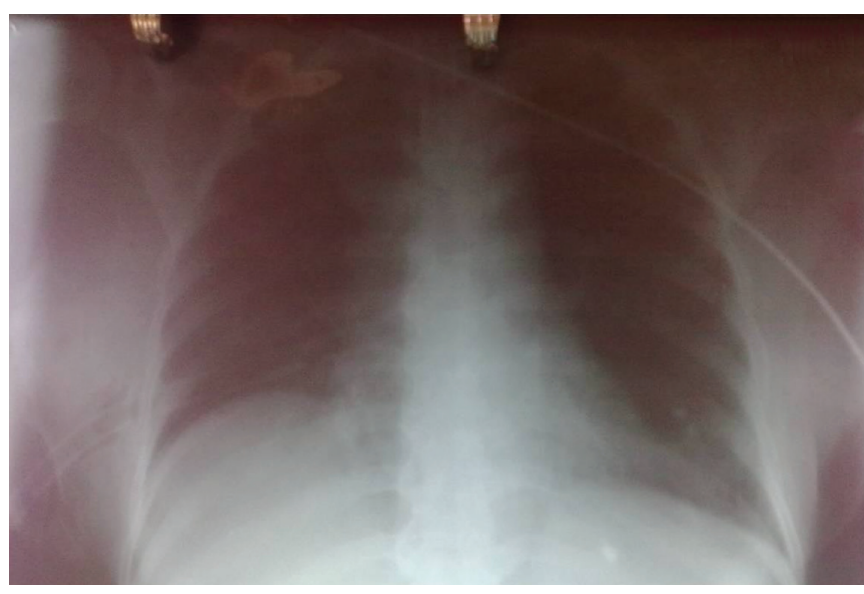

Fig. 2: Post-inter-costal drainage on day 1

persisted even after that and hence was started on AKT. Patient responded well to AKT and was discharged after removal of ICD after 26 days.

\section{DISCUSSION}

Tension pneumothorax occurs when air enters the pleural space during inspiration, but owing to ball-valve action cannot escape during expiration. The most reliable signs of tension pneumothorax are tachycardia, decreased breath sounds, hyper-resonance, and hypotension associated with hypercarbia and hypoxia.

Pneumothorax occurring during general anesthesia is a rare event but potentially dangerous problem, accounting for less than $3 \%$ of anesthesia complications. ${ }^{1}$

The most common causes are regional blocks $(40 \%$ of cases), airway instrumentation (19\%), barotrauma $(16 \%)$, and placement of central venous lines $(7 \%)^{2,3}$ Patients with chronic obstructive pulmonary disease are at increased risk of spontaneous pneumothorax. ${ }^{4}$ It is seen commonly during laparoscopic procedures. ${ }^{5-7}$ Spontaneous rupture of preexisting bullae ${ }^{8}$ may lead to pneumothorax, especially in smokers and young males. Barotrauma due to mechanical ventilation associated with risk factors like high airway pressures, stiff lungs, volume cycling, unregulated manual inflation, obstruction of endotracheal tube, excessive positive end-expiratory pressure, and endobronchial intubation is a cause of pneumothorax in $0.5-38 \%$ of critically ill patients. ${ }^{9-11}$ Incidence of delayed pneumothorax has been reported to be $0.4 \%$ (asymptomatic in $22 \%$ and tension pneumothorax in $22 \%) .{ }^{12}$ Occasionally a tension pneumothorax may be bilateral. $^{13,14}$

Under anesthesia, patient cannot complain of usual symptoms like respiratory distress, chest pain. Use of intermittent positive pressure ventilation (IPPV) with $\mathrm{N}_{2} \mathrm{O}$ may increase the risk of tension pneumothorax. 
The diagnosis of pneumothorax rests on high clinical suspicion if there is unexpected cardiorespiratory decompensation.

Pneumothorax needs to be differentiated from bronchospasm, pulmonary edema, pulmonary embolism, and pulmonary aspiration. Rapidly deteriorating general condition in spite of ventilation with $100 \%$ oxygen after general anesthesia in the absence of a predisposing cause should alert the anesthetist to the possibility of tension pneumothorax. The standard emergency treatment in these cases is a wide-bore needle placement in midclavicular line in 2nd intercostal space or if possible immediate ICD insertion. ${ }^{15,16}$

The diagnosis of pneumothorax in our patient was done immediately, before any hemodynamic instability could occur and was treated successfully. As our patient responded to AKT later, there could be a possibility of bulla secondary to tuberculosis that might have ruptured during IPPV leading to pneumothorax.

\section{CONCLUSION}

Intraoperative pneumothorax is a life-threatening emergency that requires rapid diagnosis and appropriate treatment.

\section{REFERENCES}

1. Cheney FW, Posner KL, Caplan RA. Adverse respiratory events infrequently leading to malpractice suits: a closed claims analysis. Anesthesiology 1991 Dec;75(6):932-939.

2. Bacon AK, Pair AD, Williamson JA, Webb RK, Chapman MJ. Crisis management during anesthesia: pneumothorax. Qual Saf Health Care 2005 Jun;14(3):e18.
3. Gupta N, Wadhawan S, Misra A, Anand R, Girdhar KK, Jai P. Intra operative pneumothorax in a case of phaeochromocytoma for bilateral adrenalectomy. J Anaesth Clin Pharmacol 2008 Apr-Jun;24(2):246-248.

4. Zollinger A, Zaugg M, Weder W, Russi EW, Blumenthal S, Zalunardo MP, Stoehr S, Thurnheer R, Stammberger U, Spahn DR, Pasch T. Video-assisted thoracoscopic volume reduction surgery in patients with diffuse pulmonary emphysema: gas exchange and anesthesiological management. Anesth Analg 1997 Apr;84(4):845-851.

5. Henry JF, Defechereux T, Raffaelli M, Lubrano D, Gramatica L. Complications of laparoscopic adrenalectomy: results of 169 consecutive procedures. World J Surg 2000 Nov;24:1342-1346.

6. Seow LT, Khoo ST. Unilateral pneumothorax: an unexpected complication of laparoscopic cholecystectomy. Can J Anaesth 1993 Oct; 40(10):1000-1001.

7. Heddle RM, Platt AJ. Tension pneumothorax during laparoscopic cholecystectomy. Br J Surg 1992 Apr;79(4):374.

8. Sahn SA, Heffner JE. Spontaneous pneumothorax. N Engl J Med 2000 Mar 23;342(12):868-874.

9. Petersen GW, Baier H. Incidence of pulmonary barotrauma in a medical ICU. Crit Care Med 1983 Feb;11(2):67-69.

10. Hall, JB.; Schmidt, GA.; Wood, LDH. Principles of critical care. New York: McGraw-Hill; 1992. p. 590-592.

11. De Lassence A, Timsit JF, Tafflet M, Azoulay E, Jamali S, Vincent F, Cohen Y, Garrouste-Orgeas M, Alberti C, Dreyfuss D, et al. Pneumothorax in the intensive care unit: incidence, risk factors, and outcome. Anesthesiology 2006 Jan;104(1):5-13.

12. Plewa MC, Ledrick D, Sferra JJ. Delayed tension pneumothorax complicating central venous catheterization and positive pressure ventilation. Am J Emerg Med 1995 Sep;13(5):532-535.

13. Patkar G. Bilateral tension pneumothorax and massive surgical emphysema during anesthesia. Indian J Anaesth 2004;48(3):221-223.

14. Rastogi PN, Wright JE. Bilateral tension pneumothorax under anesthesia. Anesthesia 1969 Apr;24(2):249-252.

15. Bilateral Tension Pneumothorax. Available at http//www. emedicine.com/MED/topic 2793. htm, Section 6.

16. Gaba DM, Fish KJ. Howard, SK. Crisis management in anesthesiology 1994. 